\title{
Listeriosis in the far South of Brazil: neglected infection?
}

\author{
Dulcinéa Blum-Menezes ${ }^{[1]}$, Ivânia Deliberalli[1], Najara Carneiro Bittencourt ${ }^{[1]}$, \\ Carlus Augustu Tavares do Couto ${ }^{[1]}$, Liana Nunes Barbosa ${ }^{[1]}$, \\ Alessandro Marques dos Santos ${ }^{[2]}$ and Gabriel Godinho Pinto ${ }^{[3]}$
}

[1]. Laboratório Genética de Microrganismos, Departamento de Microbiologia e Parasitologia, Instituto de Biologia, Universidade Federal de Pelotas, Pelotas, RS [2]. Hospital Universitário São Francisco de Paula, Universidade Católica de Pelotas, Pelotas, RS. [3]. Programa de Pós-Graduação em Patologia, Universidade Federal de Ciências da Saúde de Porto Alegre, Porto Alegre, RS.

\begin{abstract}
Listeriosis is an under-diagnosed and under-reported infection; however, listeriosis is not a compulsorily notifiable disease in Brazil. We provide an overview of the rates of listeriosis in the United States of America (USA), Europe, Latin America, and Brazil during the past decade. We also report a case of miscarriage caused by listeriosis in which there was no suspicion of this infection. This overview and the case we report serve as reminders of the often-neglected threat of listeriosis and its potential to cause miscarriage while highlighting the necessity of recognizing listeriosis as a compulsorily notifiable disease in Brazil.
\end{abstract}

Keywords: Listeria monocytogenes. Listeriosis. Miscarriage. Brazil. South America.

\section{OVERVIEW}

Listeriosis is a foodborne disease that is a public health concern. More than $70 \%$ of all cases of listeriosis occur in individuals with recognized predisposing conditions, such as pregnancy. Listeriosis in pregnant women and maternal intrauterine infection caused by Listeria monocytogenes are typically mild flu-like illnesses but may lead to severe complications, such as premature delivery, miscarriage, stillbirth, and neonatal sepsis.

In the United States of America (USA), an average of 2.4 outbreaks of listeriosis per year, each representing 1,600 cases, were reported between 1998 and 2008, according to the Centers for Disease Control and Prevention (CDC), Atlanta ${ }^{1}$.

In the USA, sporadic cases of human listeriosis occur with an annual incidence of approximately 0.27 per 100,000 people ${ }^{2}$. The incidence of nonperinatal listeriosis decreased by $24 \%$ over the last 2 decades ${ }^{3,4}$, largely as a consequence of the zero-tolerance policy deployed in 1987 by the Food Safety and Inspection Service of the USA Department of Agriculture ${ }^{5}$, which prohibited the sale of ready-to-eat meats contaminated with L. monocytogenes. However, the same decrease was not observed in the frequency of perinatal listeriosis ${ }^{3,4}$.

Since 2004, the CDC has requested that listeriosis patients be interviewed using the CDC standardized Listeria Initiative

Address to: $\mathrm{Dr}^{\mathrm{a}}$ Dulcinéa Blum Menezes. Laboratório Genética de Microrganismos/ Dept $^{\circ}$ de Microbiologia e Parasitologia/IB/UFPel. Caixa Postal 354, 96001-970 Pelotas, RS, Brasil.

Phone: 5553 3275-7626

e-mail: dulceblum@uol.com.br

Received 22 January 2013

Accepted 13 May 2013 questionnaire. Together with the application of PulseNet, a molecular subtyping network for the surveillance of foodborne diseases, this measure has enabled rapid recalls of potentially contaminated products by tracing them to stores where the foods were purchased by the patients ${ }^{6}$.

However, even this zero-tolerance policy for ready-to-eat food has not prevented major outbreaks of listeriosis in the USA, where a multistate outbreak of $L$. monocytogenes infections occurred in 2011. The CDC reported that of the 147 individuals infected with $L$. monocytogenes during that outbreak, 33 died, and a woman who was pregnant at the time of illness had a miscarriage ${ }^{1}$.

In Europe, the annual epidemiology report on communicable diseases during 2011 showed a small decrease in the number of listeriosis cases between 2006 and $2009^{7}$. The overall rate of notification during 2009 ( 0.35 per 100,000 individuals) was slightly higher than that during $2008(0.31)$ but was relatively stable between 2006 and 2009, with values of 0.35 and 0.36 for 2007 and 2006, respectively ${ }^{7}$.

Sisó et al. ${ }^{8}$ described the variation in the incidence of listeriosis infection among pregnant women in Barcelona between 1985 and 2010. Over this time period, 43 cases of perinatal listeriosis were diagnosed among 82,320 hospitalized pregnant women in Barcelona (incidence $0.05 \%$ ). The incidence remained almost constant at $0.024 \%$ until 2,000 , with an increasing incidence thereafter, reaching $0.086 \%$ during the last 10 years of the study period.

Goulet et al. ${ }^{9}$ estimated the risk of listeriosis associated with pregnancy and other underlying conditions among residents of France. They reported that when the incidence of listeriosis ranges from 0.1 to 1 cases per 100,000 members of the general population, the frequency of listeriosis among pregnant women increases to 5.6 cases per 100,000 pregnancies, and the case fatality percentage is $31 \%$. 
In Denmark, during the period from 1989 to 2008, the annual incidence of listeriosis varied between 0.4 and 1.1 per 100,000 members of the general population ${ }^{10}$. In the United Kingdom, Khatamzas et al. ${ }^{11}$ reported that the incidence of listeriosis was twice as high between 2000 and 2008 compared with the incidence between 1990 and 2000.

Data collected in Latin American show a similar recent increase in rates of listeriosis. In a major private maternity hospital in Santiago, Chile, the frequency of neonatal listeriosis increased 15-fold between 2007 and 2008, and some reports ${ }^{12}$ of listeriosis were described in the literature related to abortions and preterm deliveries.

In Brazil, listeriosis is not a compulsorily notifiable disease. To date, few sporadic cases of listeriosis have been reported, and no outbreaks have been reported among non-hospitalized patients in Brazil. Martins et al. ${ }^{13}$ reported an outbreak of listeriosis that affected 6 elderly hospitalized patients in Rio de Janeiro.

There are reports of L. monocytogenes in foods in the State of Rio Grande do Sul, specifically in the City of Pelotas ${ }^{14-16}$, although no cases of listeriosis were diagnosed. In 2011, an etiological investigation of a miscarriage case revealed histological evidence suggestive of listeriosis following the analysis of a placental sample even though the presence of L. monocytogenes was never demonstrated using microbiological methods ${ }^{17}$. In the same year, according to the Municipal Health Department of Pelotas, the average monthly number of curettages after miscarriage was 37.5. However, to our knowledge, there has been no report of a case of listeriosis associated with a miscarriage.

\section{CASE REPORT}

Herein, we report a case of listeriosis in Pelotas, Brazil, in which the diagnosis was confirmed by the isolation of L. monocytogenes from placental membrane tissue without prior clinical suspicion of this infection.

On February 23, 2011, a 21-year-old afebrile woman in her twelfth week of pregnancy was admitted for an emergency caesarean section due to placental abruption. Placental tissue and blood samples were collected in addition to a vaginal swab and a rectal swab for microbiological analysis during curettage procedures. The samples were directly inoculated in half Fraser broth (Laborclin, PR, Brazil) and cultured at $30^{\circ} \mathrm{C}$ for 5 days. Aliquots of each culture were then plated on Agar Listeria (Ottaviani \& Agosti; ALOA, Laborclin) and incubated at $37^{\circ} \mathrm{C}$ for 7 days. Typical colonies (short Gram-positive rods, motile at $25^{\circ} \mathrm{C}$, oxidase-negative, positive for both aesculin hydrolysis and catalase) were characterized at the molecular level using polymerase chain reaction (PCR) and restriction fragment length polymorphism (RFLP) analyses, according to procedures described by Paillard et al. ${ }^{18}$. From the placental membrane tissue, colonies with characteristics that were typical of L. monocytogenes were isolated, and the presence of the pathogen was confirmed using RFLP molecular profiling. The PCR-amplified product, an 890-base pair (bp) fragment, was cleaved by the enzyme XmnI to generate 770- and 120-bp fragments and by the enzyme $C f o$ I to generate 470-, 170-, 130-, and 120-bp fragments. These cleavage patterns confirmed the isolation of $L$. monocytogenes. The vaginal and rectal samples were negative for L. monocytogenes.

\section{DISCUSSION}

In the present case, the infection was characterized by the absence of prodromal signs, which caused the diagnosis to be inconclusive. Unfortunately, the placental sample that enabled a causal diagnosis to be made was obtained belatedly, precluding an early diagnosis.

Listeriosis can affect neonates even if the mother does not present symptoms of listeriosis. Accordingly, Sisó et al. ${ }^{8}$ reported the diagnosis of neonatal listeriosis in 5 babies whose mothers were completely asymptomatic. Similarly, following a listeriosis outbreak ${ }^{19}$ of 16 babies with maternal-neonatal cases of listeriosis, 2 babies were born to asymptomatic mothers. This phenomenon may be explained by vertical transmission of the infection despite the fact that it does not produce a systemic inflammatory response in the mother ${ }^{8}$.

A negative blood culture does not eliminate the possibility of listeriosis in cases of miscarriage. The ability of L. monocytogenes to colonize and persist in the gallbladder and cause chronic infection demonstrates its ability to survive within the various microenvironments of the gastrointestinal tract. Because L. monocytogenes has an intracellular life cycle ${ }^{19}$, infection does not necessarily manifest clinically with an immune response typical of a bacterial infection.

This review and case report serve as a reminder that listeriosis is often not considered as a cause of miscarriage and emphasize the necessity of classifying listeriosis as a compulsorily notifiable disease in Brazil.

\section{ACKNOWLEDGMENTS}

We thank the obstetric staff of the University Hospital of UCPEL for their use of proper procedures for obtaining samples.

\section{FINANCIAL SUPPORT}

This work was supported by Fundação de Amparo a Pesquisa do Estado do Rio Grande do Sul (FAPERGS; Brazil) as part of the Research Projects for the Brazilian Public Health System (Projetos de Pesquisa para o SUS - PPSUS; Process 09/0061-3).

\section{REFERENCES}

1. Centers for Disease Control and Prevention (CDC). Multistate outbreak of listeriosis associated with Jensen Farms cantaloupe-United States, August-September 2011. MMWR Morb Mortal Wkly Rep 2011; $60: 1357-1358$. 
2. Centers for Disease Control and Prevention (CDC). Preliminary FoodNet data on the incidence of infection with pathogens commonly transmitted through food-10 states, 2007. MMWR Morb Mortal Wkly Rep 2007; 57: 366-370.

3. Voetsch AC, Angulo FJ, Jones TF, Moore MR, Nadon C, McCarthy P, et al. Reduction in the incidence of invasive listeriosis in foodborne diseases active surveillance network sites, 1996-2003. Clin Infect Dis 2007; 44:513-520. Epub 2007 Jan 8. Erratum in: Clin Infect Dis 2011; $53: 404$.

4. Bennion JR, Sorvillo F, Wise ME, Krishna S, Mascola L. Decreasing listeriosis mortality in the United States, 1990-2005. Clin Infect Dis 2008; 47:867-874.

5. Food Safety and Inspection Service. Testing for Listeria monocytogenes. Federal Register 1987; 52:7464-7465.

6. Centers for Disease Control and Prevention (CDC). Outbreak of invasive listeriosis associated with the consumption of hog head cheese-Louisiana, 2010. MMWR Morb Mortal Wkly Rep 2011; 60:401-405.

7. European Centre for Disease Prevention and Control (ECDC). Annual Epidemiological Report 2011. Reporting on 2009 surveillance data and 2010 epidemic intelligence data. Stockholm: ECDC; 2011.

8. Sisó C, Goncé A, Bosch J, Salvia MD, Hernández S, Figueras F. Listeriosis in pregnancy: a secular trend in a tertiary referral hospital in Barcelona. Eur J Clin Microbiol Infect Dis 2012; 31:2125-2132.

9. Goulet V, Hebert M, Hedberg C, Laurent E, Vaillant V, De Valk H, et al. Incidence of listeriosis and related mortality among groups at risk of acquiring listeriosis. Clin Infect Dis 2012; 54:652-660.

10. Kvistholm JA, Ethelberg S, Smith B, Moller NE, Larsson J, Molbak K, et al. Substantial increase in listeriosis, Denmark 2009. Euro Surveill 2010; 15:19522.

11. Khatamzas E, Hughes H, Grant KA, McLauchlin J, Bowler IC. The increasing prevalence of listeriosis-what are we missing? QJM 2010; 103:519-522.
12. Noriega R LM, Ibáñez VS, González AP, Yamamoto CM, Astudillo DJ, González VM, et al. Listeria monocytogenes: report of a rise in pregnant women and literature review. Rev Chilena Infectol 2008; 25:342-349.

13. Martins IS, Faria FC, Miguel MA, Dias MP, Cardoso FL, Magalhães AC, et al. A cluster of Listeria monocytogenes infections in hospitalized adults. Am J Infect Control 2010; 38:e31-6. Epub 2010 Jun 8. Rebello, Renata Fernandes [corrected to Rabello, Renata Fernandes]. Erratum in: Am J Infect Control 2010; 38:849.

14. Mendonça KS, Michael GB, Von Laer AE, Menezes DB, Cardoso MRI, Silva WP. Genetic relatedness among Listeria monocytogenes isolated in foods and food production chain in Southern Rio Grande do Sul, Brazil. Food Control 2012; 28:171-177.

15. Laer AEV, Lima AS, Trindade OS, Andriguetto C, Destro MT, Silva WP. Characterization of Listeria monocytogenes isolated from a fresh mixed sausage processing line in Pelotas-RS by PFGE. Braz J Microbiol 2009; 40:574-582.

16. Silva WP, Techera SBC, Jantzen MM, Laer AEV, Lima AS, Mata MM. Listeria monocytogenes en quesos tipo Minas producidos artesanalmente y comercializados en Pelotas, RS, Brasil. Alimentaria 2004; 359:57-60.

17. Blum-Menezes D, Deliberalli I, Cunha-Schiavon V, Yazie LM, Silveira LI, Jannke HA, Análise Microbiológica e Histológica de Listeriose em amostras clínicas de pacientes em processo de abortamento em Pelotas no Rio Grande do Sul. Laes\&Haes 2012; 197:134,138,140-142.

18. Paillard D, Dubois V, Duran R, Nathier F, Guittet C, Caumette P, et al. Rapid identification of Listeria species by using restriction fragment length polymorphism of PCR-amplified 23S gene fragments. Appl Environ Microbiol 2003; 69:6386-6392.

19. Gaulin C, Ramsay D, Bekal S. Widespread listeriosis outbreak attributable to pasteurized cheese, which led to extensive cross-contamination affecting cheese retailers, Quebec, Canada, 2008. J Food Prot 2012; 75:71-78.

20. Tilney LG, Portnoy DA. Actin filaments and the growth, movement, and spread of the intracellular bacterial parasite, Listeria monocytogenes. J Cell Biol 1989; 109:1597-1608. 